\title{
The Choice of Organizational Structure in the Internet Era: Flattening and Decentralization — Based on Perspective of Dynamic Capabilities
}

\author{
Xiaoling Wang ${ }^{1,}$, , Yan Chen ${ }^{2}$, Bo Yang ${ }^{1}$ \\ ${ }^{1}$ School of Business, Jiangxi Normal University, Nanchang, China \\ ${ }^{2}$ Hangzhou Vanke Property Services Co. Ltd, Hangzhou, China \\ Email address: \\ xiaoling6302@sina.com (Xiaoling Wang), chen245@vanke.com (Yan Chen) \\ ${ }^{*}$ Corresponding author
}

To cite this article:

Xiaoling Wang, Yan Chen, Bo Yang. The Choice of Organizational Structure in the Internet Era: Flattening and Decentralization —— Based on Perspective of Dynamic Capabilities. American Journal of Management Science and Engineering. Vol. 5, No. 4, 2020 , pp. 42-50. doi: 10.11648/j.ajmse.20200504.11

Received: August 2, 2020; Accepted: August 13, 2020; Published: August 25, 2020

\begin{abstract}
In the Internet era, when information technology permeates into firm's business process day by day, it is an urgent task to win competitive advantage by obtaining dynamic capabilities in super-competitive environment. This paper constructs the research model and puts forward the theoretical hypothesis on the basis of combing the existing relevant literature. Based on the mature organizational structure and dynamic ability scale, 328 valid sample data were empirically tested. The results show that the each dimension of organizational structure has a significant positive impact on the dynamic capabilities of the enterprise, that is, the flattening and the decentralization of the organization have a significant positive effect on the sense ability, the integration ability and the innovation ability. Then it puts forward the management enlightenment, limitation and research prospect. The contribution of this paper is to establish the research framework of organizational structure and dynamic capabilities from the perspective of dynamic capabilities, and point out that flattening and decentralization is a reasonable choice of enterprise organizational structure in the Internet era. This organizational structure is helpful for enterprises to sense the rapid changes of the market in time, efficiently integrate the internal and external resources, and obtain iterative and rolling competitive advantage through the innovation of technology and management.
\end{abstract}

Keywords: Internet Era, Organizational Structure, Dynamic Capabilities, Flattening, Decentralization

\section{Introduction}

With the rapid development of the Internet, the competition among enterprises is becoming more and more fierce, the market environment is becoming more and more complex, and the advantages obtained by enterprises in the past steady state environment are constantly eroded. Having dynamic capability is the key for enterprises to obtain sustainable competitiveness in an environment fulling of uncertainty [1]. Dynamic capabilities is the ability of enterprises to integrate, establish and reconstruct internal and external resources to modify management patterns and thus adapt to dynamic and complex environmental changes $[2,3]$. Because dynamic capabilities is the ability of organization to adapt dynamically to complex environment, more and more enterprises feel a high sense of crisis and begin to seek change through organizational structure transformation in order to adapt to the rapid development of Internet era. For example, Japan Kyocera Group through the empowerment of the formation of full participation in the amoeba operation model, Haier Group's Self-management body with inverted triangle as the main structure, And Alibaba Group's co-operative business community. Many enterprises have tried to change the organizational structure. Although the above cases enjoy good reputation in academic and business circles, there are some problems that can not be ignored. Haier's self-management body had achieved very good results in the practice, but the effect of some individuals still were not very ideal [4]. What variables play a major role in the dynamic environment is worth exploring. 
Besides, Alibaba had undergone many organizational adjustments such as business group structure, and the goal of each adjustment was to adapt to the more and more quickly market changes [5]. Therefore, it is a realistic challenge that an organizational structure can maintain flexibility to achieve continuous innovation and make the organization synergistic efficiency for the enterprise sustainable development in the Internet era.

Dynamic capabilities is regarded as an important force for enterprises to acquire and maintain sustainable competitiveness, and it is the most important mission of enterprises in the Internet era to perceive market changes in time and integrate resources quickly to innovate on this basis, so as to meet the increasingly diversified and individualized needs of customers. Because of its importance to enterprises to build sustainable competitiveness in the Internet era, dynamic ability has become the core theory in the field of enterprise management and has been widely concerned by scholars. and in the construction of dynamic ability, previous studies mainly from the perspective of resources, behavior and cognition [6], pay less attention to the phenomenon of organizational structure change, and the empirical research on the relationship between organizational structure and dynamic ability in the internet age is even more rare. This paper tries to establish a connection between the change of organizational structure and the dynamic ability of enterprises in the Internet era.

\section{Literature Review}

Since 1947 Max Weber the "family structure" was proposed, and this pyramid structure has been widely used. However, the advent of the Internet era has accelerated the change of the external environment of enterprises, the change of user needs is unpredictable, and the disadvantages of the pyramid structure applied to the stable environment are gradually revealed. In 1988, Drucker pointed out that 20 years later, the typical large enterprise, its management would be less than half today, and the management staff would be less than a third of today's [7]. Peters also expressed his support for Drucker's theory of flexible organization, and predicted that the family structure would surely go to the end [8]. Zhao Wen believed that the application of Internet information technology would weaken or even eliminate the the intermediate level, and the functional management department would be greatly reduced. The concept of strict hierarchy would gradually become weak, thus forming a flattening network organization [9]. Enterprises pay more and more attention to the survival and development of equality, openness, sharing and coexistence, and the organizational change presents the trend of ecological, unbounded, platform and self-organization [10]. The existing research had paid attention to the perfect organizational structure, which is bound to adapt to the changes of internal and external environment and conditions, so as to support the steady growth and development of enterprises in the dynamic changing environment.

\subsection{Evolution of Organizational Structure}

Mintzberg defined organizational structure as the way tasks assigned and coordinated. This definition raised two most basic problems: specialization and coordination [11]. Daft had proposed that organization structure includes three main points: (1) formal report relationship in an organization including the levels of organization and Management range; (2) determine the way of organization integrate; (3) Institutional design for cross-sectoral communication, collaboration and resource integration [12]. According to contingency theory, organizational structure should match organizational strategy, while strategy needs to change with the external environment [13]. The enterprise organization structure had experienced the traditional function system, the modern ministry system and the matrix system, the postmodern changes in network structure [14]. With the deep integration of Internet technology, enterprise organization structure is faced with the enormous innovation pressure and the change challenge, the enterprise urgently needs to seek a kind of flexible, most adaptable structure which will give employees more autonomy and help company adapt quickly to the new environment [15].

According to the characteristics of organizational design, organizational dimensions could be divided into two categories: structural dimensions and relevance dimensions [12]. The structural dimension is used to measure and compare the internal characteristics of the organization, and the correlation dimension reflects the characteristics of the whole organization. This paper mainly examines the relationship between the internal characteristics of organizational structure and the dynamic capabilities, and only takes the structural dimension of organization as the research object. The existing literature has not reached an agreement on the dimension division of organizational structure. There are more rules of organization hierarchy and formalization in mechanical structure, the degree of decision-making centralization is high, the scope of management is small, and the communication process is more dependent on vertical communication. The organizational level of organic structure is flat, the formal rules are less, the organization is decentralized, the management scope is wider, the communication mode is horizontal, the information can be transmitted in many directions, and it has more advantages in the flexibility, informality and reasonable authorization of the management relationship [16]. Wang Tao et al. divided the organic organizational structure into three dimensions: flat degree, decentralization degree and multi-function of employees [17]. Scholar Cardinal used decentralization and regularization to measure organizational structure [18]. Decentralization reflects the degree to which employees enjoy decision making power, and formalization reflects the degree to which organizations use formal rules and procedures to regulate employee behavior [19].

\subsection{Dynamic Capabilities and Dimension}

Teece, Pisano and Shuen first put forward the concept of 
dynamic capabilities, which is the ability of enterprises to integrate, build and reconstruct internal and external competencies to adapt to the rapidly changing external environment $[2,3]$. Since then, many scholars had defined the dynamic capabilities from different angles. They thought that the dynamic capabilities was the process of using resources, that was, the process of integrating, reconstructing, acquiring and releasing resources, in order to match the changes in the market based on the perspective of the resources [20]. Based on the view of organizational learning, it was considered that dynamic capabilities was a stable and collective learning behavior model, through which enterprises can systematically produce and change operational practices, thus pursuing performance improvement [21]. From the point of view of technological innovation, it was considered that dynamic capabilities was the strategy and organizational management practice of enterprises in order to create and seize new technological opportunities and establish new resource and capability structure under the condition of technological paradigm change [22]. There are many other points that will not be repeated.

About the dimension of dynamic capabilities, scholars analyzed it through the elements of ability, environment and organization. By using fuzzy cluster analysis, Luo Min analyzed 39 classical literatures of dynamic capabilities in the past, and put forward four dimensions: the ability to perceive market orientation, the ability to coordinate the relationship of enterprise social network, the ability of learning absorption of organization and the ability of communication coordination and integration [23]. Wang and Ahmed understood dynamic capabilities as adaptive, absorptive and innovative abilities [24]. Huang divided dynamic capabilities into resource allocation ability, innovation ability and customization ability according to the characteristics of mobile Internet environment [25].

This paper adopts the definition of Teece et al in 1997, due to the high degree of recognition of this division in academic circles, and divides it into three dimensions: perception ability, integration ability and innovation ability. We believe that perception refers to the ability of enterprises to scan, search, and identify market opportunities quickly in a highly competitive turbulent environment. This ability is mainly through routine, processes and mature path within the enterprise to identify market opportunities in the ecosystem in a timely manner. Integration ability refers to the ability of enterprises to reconfigure existing internal and external resources to adapt to the changes of external environment. It is an innovative application of existing knowledge by integrating knowledge and capabilities. Innovation ability refers to the ability of enterprises to acquire new technologies and processes and commercialize them through the use of internal and external knowledge they have to provide products and services to the market.

\subsection{Linkages Between Organizational Structure and Dynamic Capabilities}

Chen \& Liu believed that organizational structure is the basic mechanism to ensure that organizations and members can learn and create knowledge, and play an important role in the learning process. The organizational structure focuses on the impact on resource coordination and resource consolidation. Information was the basis of organization's insight into the environment. The more organizational levels, the more unfavorable information communication was, and the speed and quality of information transmission were affected by the level of organization. The ability to gain insight into the environment was also affected by the management range, which affects the speed of information processing by managers [16]. The improvement of enterprise dynamic capabilities could be classified into two problems: one was to provide a "platform" for employees to give full play to their wisdom; the other was to let employees have enough "will" to play their own wisdom. This platform specificly was the organizational structure within the enterprise [26]. In order to obtain dynamic capabilities, the organizational structure of the hierarchical system needed to be reconstructed, and more power was given directly to the first line managers and employees to form an inverted triangular organizational structure [4]. The flexibility of organizational structure was the basis for enterprises to keep dynamic. Enterprises should establish scientific organizational structure according to the characteristics of the environment, such as designing flat organization, project-based organization, universal dual organization, which could reduce communication barriers between departments, accelerate the efficiency of knowledge transformation and transfer, improve the effect of knowledge learning, promote technological innovation and product innovation [27].

About the influence of organizational structure on dynamic capabilities, Tsoukas \& Mylonopoulos considered that organization was a knowledge system based on the study of the relationship between knowledge, learning and dynamic capabilities. The organization created new knowledge through learning and institutionalizing the new knowledge so as to better enhance the dynamic capabilities [28]. Hence, it was very meaningful to explore which organizational structure could provide the most suitable conditions for organizational learning [29]. Building flexible organizational structures in dynamic environments, especially the Internet, wouldl have a positive impact on the learning process [30]. It was the tend to adopt decentralized organizations or organizational departments, and establish flat organizations of middle level functional managers through organizational design to promote business diversification, which was more conducive to the formation of dynamic capabilities of enterprises [31].

\section{Research Design}

\subsection{Research Model}

Based on theoretical review and related literature analysis, this study puts forward a research model of organizational structure affecting enterprise dynamic ability in the Internet era. According to the Internet theory and organizational 
structure theory, the organizational structure is composed of two dimensions: flat and decentralized. At the same time, on the basis of defining the concept of dynamic ability, the dynamic capabilities divided into three dimensions: perception ability, integration ability and innovation ability. Referring to the existing mature scale, the measurement scale of organizational structure and dynamic ability is designed. The research model of this study is as follows (Figure 1):

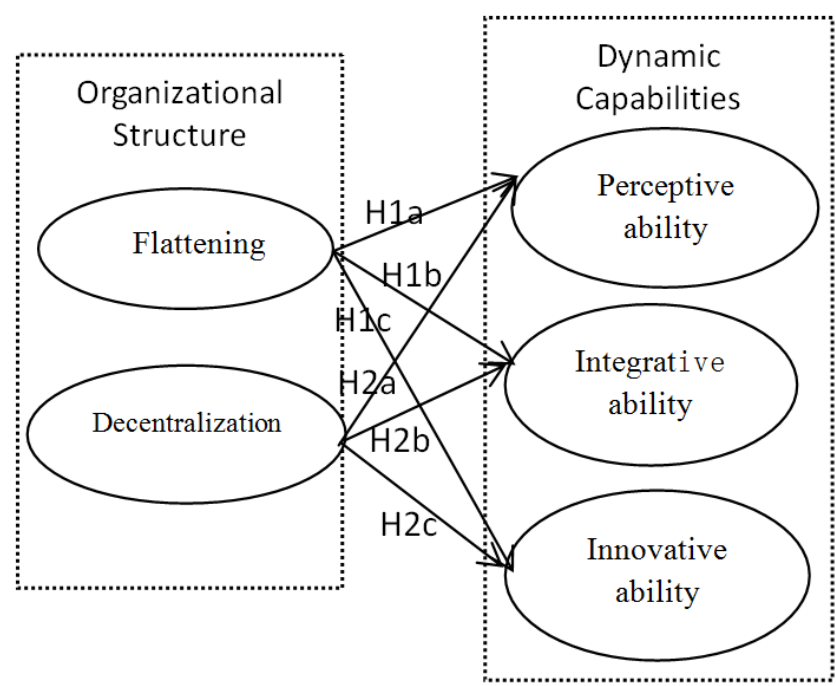

Figure 1. Construction model between organizational structure and dynamic capabilities.

\subsection{Variable Measurement}

The two measurement scales of organizational structure and dynamic capabilities are used in this study. The organizational structure adopts two dimensions: flattening and decentralization. The measurement questions refer to the scale designed by Huang [32]. The dynamic capabilities adopts three dimensions: perceptive ability, integrative ability and innovative ability. The measurement scale draws lessons from Zahar \& George [31], Salunke [33] and He \& Li [34] measurement correlation scale. All items are measured using the Richter Level 5 scale, with "1 indicating complete non-conformance "and "5 indicating complete compliance ". In order to ensure the reliability and validity of the scale, a small sample test and confirmatory factor analysis are carried out on the scale, and the original scale is properly trimmed in combination with the research situation.

\subsection{Research Hypotheses}

As a force to change society, the Internet has changed and reconstructed people's social life and business cooperation model. While the traditional supply-oriented business model is gradually dying out, demand-oriented Internet business model and value creation are emerging [35]. The Internet greatly expands the channels for individuals to output and receive information, and greatly reduces the cost of mass communication. Individual demand is fully excavated to highlight the diversification of market demand, which requires enterprises to change the organizational structure model to enhance market perception, integration and innovation ability.

The application of Internet information technology makes enterprise organizations weaken or even cancel the middle level of rights, thus forming a "flat" network organization structure [9]. By learning to create new knowledge and institutionalizing new knowledge to the organizational level, organizations can better enhance the dynamic capabilities of enterprises [28]. Therefore, it is very meaningful to explore what organizational structure can provide the most suitable conditions for organizational learning. Rindova and Kotha studied that the continuous deformation of tissue forms was one of the prelude to the development of dynamic capabilities [36]. The establishment of flexible organizational structure in dynamic environment, especially in Internet environment, will play an important role in the process of dynamic capabilities construction.

\subsubsection{Effect of Flattening on Dynamic Capabilities}

Flatness mainly measured the level of power and management in organizational structure [32]. In the Internet era, facing on complex changes of the external environment and fierce industry competition, more and more enterprises will reduce the power level and expand the management range as the goal of organizational structure adjustment. Teece et al. explain the formation of dynamic capabilities through three dimensions: process, position and path [2]. Flattening can facilitate horizontal communication and coordination within the organization and accelerate the free flow of knowledge and information within the organization, thus it can promote cross-functional cooperation, learning and innovation among business units [37]. Jensen and Meckling put forward the concept of know-how in the discussion of organizational structure. Know-how refers to the knowledge requires high cost and was easily "distorted" to be converted between different members, such as operational and practical knowledge, quality and technical improvement knowledge of grass-roots employees [38]. Compared with the previous hierarchical organizational structure, flattening provided a flexible and multidimensional and multi-directional information transmission channel to help enterprises enhance their ability to perceive opportunities, integrate and motivate team innovation performance in the rapidly changing market environment [39]. The study therefore assumes that:

H1a: flattening positively affects perceptive ability.

H1b: flattening will positively affect integrative ability.

H1c: flattening will positively affect innovative ability.

\subsubsection{Effect of Decentralization on Dynamic Capabilities}

Decentralization mainly measured the degree of participation of grass-roots employees in enterprise decision-making, and the decentralization of organizational structure transferred power from the top decision makers in the organization to the employees in each small and micro organization, which helped to form a working atmosphere of full participation. It helped employees make quick decisions based on first-line market responses [40]. The first-line employees sent instructions upward according to the customer 
needs, forcing the superior resource platform and strategic level to provide resources, funds and professional support, which to a large extent enhanced the organization's ability to integrate resources. Only through the integration of resources could enterprises enhance their dynamic capabilities [24]. These abilities ensured the improvement of enterprise performance and promoted the growth of enterprises. Innovation was the ability of an enterprise to acquire and commercialize new technologies or processes through the use of its internal and external knowledge to provide new products or services to the market. [41] It is emphasized that enterprises acquire market knowledge and technical knowledge from inside or outside and integrate them to obtain new ideas, while organizational decentralization greatly mobilizes employees' learning enthusiasm and self-sharing consciousness, while stimulating employees' creativity and exploration power. Therefore we have following assumes:

H2a: Decentralization positively affects perceptive ability.

$\mathrm{H} 2 \mathrm{~b}$ : Decentralization positively affects the integrative ability

H2c: Decentralization will positively affect innovative ability.

\section{Data Analysis}

This study mainly carries on the data collection through the network platform and the spot distribution questionnaire. The main objects of the questionnaire survey include the general staff of enterprises, grass-roots managers and middle and senior managers. Considering the importance of the authenticity and validity of the data to the research results, the questionnaire: (1) enterprises not affected by the development of the Internet in the process of management. (2) Choose the same option or repeat regularly to fill in the missing. (3) questionnaires remaining a lot of blank. (4) questionnaires Duplicating IP address. A total of 431 questionnaires were distributed. After excluding the above invalid questionnaires, the effective recovery rate was 76.1 and 328 valid questionnaires were obtained.

\subsection{Descriptive Statistical Analysis}

The descriptive statistical analysis results of the questionnaire survey are shown in Table 1. Among the respondents, $55.2 \%$ were male, $44.8 \%$ were female, and the proportion of men and women was moderate. Most of the respondents had certain knowledge literacy. The survey objects are mostly grass-roots employees and middle-level managers, and the feeling of organizational structure change is obvious. The nature of the company is evenly distributed; the company is established for more than 5 years, the company size of more than 500 people account for the overall 39, in line with the e-commerce era of enterprise development. Only $4.9 \%$ of the respondents thought that the Internet had no effect on the management of their company. $95.1 \%$ of the respondents felt the impact of the development of the Internet era on the management of the company, thus ensuring the reliability of the questionnaire data.
Table 1. Descriptive statistical tables of survey enterprises.

\begin{tabular}{|c|c|c|c|}
\hline Item & Indicate & Number & Proportion \\
\hline \multirow{2}{*}{ Sex } & Male & 181 & 55.2 \\
\hline & Female & 147 & 44.8 \\
\hline \multirow{3}{*}{ Education } & College & 118 & 36.0 \\
\hline & Undergraduate & 162 & 49.4 \\
\hline & Master & 48 & 14.6 \\
\hline \multirow{3}{*}{ Position } & Grassroot & 126 & 38.4 \\
\hline & Middle & 192 & 58.6 \\
\hline & Top management & 10 & 3.0 \\
\hline \multirow{4}{*}{ Property } & SOE & 84 & 25.6 \\
\hline & Mixed enterprises & 126 & 38.4 \\
\hline & $\begin{array}{l}\text { Foreign-funded } \\
\text { enterprises }\end{array}$ & 76 & 23.2 \\
\hline & Private enterprises & 42 & 12.8 \\
\hline \multirow{4}{*}{ Scale } & $<50$ & 49 & 14.9 \\
\hline & $51-500$ & 151 & 46.1 \\
\hline & $501-1000$ & 58 & 17.7 \\
\hline & $>1000$ & 70 & 21.3 \\
\hline \multirow{3}{*}{ Age (year) } & $1-5$ & 107 & 32.6 \\
\hline & $6-10$ & 93 & 28.4 \\
\hline & $>10$ & 128 & 39.2 \\
\hline \multirow{4}{*}{$\begin{array}{l}\text { Internet } \\
\text { impact }\end{array}$} & None & 16 & 4.9 \\
\hline & Minor & 167 & 50.9 \\
\hline & Serious & 97 & 29.6 \\
\hline & Fatal & 48 & 14.6 \\
\hline
\end{tabular}

\subsection{Scale and Research Hypothesis Test}

\subsubsection{Scale Test of Reliability and Validity}

Cronbach's $\alpha$ coefficient is usually used to determine the reliability of the scale. The SPSS21 version was used to test the reliability and validity of the scale. The coefficients of flattening and decentralization of the organizational structure of the scale used in this paper were 0.87 and 0.85 , respectively. The coefficients $\alpha$ of the three dimensions of dynamic Capabilities, that is perceptive ability, integrative ability and innovative ability were $0.92,0.95$ and 0.92 , respectively. All the $\alpha$ were bigger than the reliability test standard value 0.7 . The data analysis results of Table 2 show that the measurement scale of organizational structure and dynamic capabilities have high internal consistency, and the scale is stable and reliable. The convergence validity of the scale is tested by average variation extraction AVE and factor load. The general AVE value is greater than 0.5 and the factor load is greater than 0.7. Data analysis results in Table 2 show that the factor load of the scale is greater than 0.7 and the AVE value is greater than 0.5 , which indicates that the scale has passed the convergent validity test. Distinguishing validity requires that the AVE of variables is greater than the correlation coefficient between variables and other latent variables. The data analysis results in Table 3 show that the scale has passed the test of distinguishing validity. Therefore, the scale adopted in this paper passed the test of reliability and validity.

Using correlation analysis to test the correlation between variables (Table 3), the analysis shows that there is a significant correlation between the dimensions of organizational structure and the dimensions of dynamic capabilities. 
Table 2. Reliability and validity test of scale.

\begin{tabular}{|c|c|c|c|c|}
\hline Variables & Items & Factor load & AVE & Cronbach's $\alpha$ \\
\hline \multirow{3}{*}{ Flattening } & F1 & 0.807 & \multirow{3}{*}{0.800} & \multirow{3}{*}{0.870} \\
\hline & $\mathrm{F} 2$ & 0.781 & & \\
\hline & F3 & 0.828 & & \\
\hline \multirow{3}{*}{ Decentralization } & D1 & 0.857 & \multirow{3}{*}{0.772} & \multirow{3}{*}{0.853} \\
\hline & $\mathrm{D} 2$ & 0.865 & & \\
\hline & D3 & 0.834 & & \\
\hline \multirow{5}{*}{ Perceptive ability } & P1 & 0.912 & \multirow{5}{*}{0.768} & \multirow{5}{*}{0.916} \\
\hline & $\mathrm{P} 2$ & 0.776 & & \\
\hline & P3 & 0.822 & & \\
\hline & $\mathrm{P} 4$ & 0.909 & & \\
\hline & P5 & 0.838 & & \\
\hline \multirow{5}{*}{ Integrative ability } & G1 & 0.737 & \multirow{5}{*}{0.850} & \multirow{5}{*}{0.947} \\
\hline & $\mathrm{G} 2$ & 0.947 & & \\
\hline & G3 & 0.951 & & \\
\hline & G4 & 0.730 & & \\
\hline & G5 & 0.956 & & \\
\hline \multirow{5}{*}{ Iinnovative ability } & V1 & 0.895 & \multirow{5}{*}{0.776} & \multirow{5}{*}{0.921} \\
\hline & V2 & 0.800 & & \\
\hline & V3 & 0.862 & & \\
\hline & V4 & 0.891 & & \\
\hline & V5 & 0.866 & & \\
\hline
\end{tabular}

Table 3. AVE root-mean- square and correlation coefficient between variables.

\begin{tabular}{llllll}
\hline & Flattening & Decentralization & Perceptive ability & Integrative ability & Iinnovative ability \\
\hline Flattening & 0.893 & & & & \\
Decentralization & $0.282^{* *}$ & 0.877 & & & \\
Perceptive ability & $0.378^{* *}$ & $0.156^{* *}$ & 0.876 & 0.921 & $0.164^{* *}$ \\
Integrative ability & $0.490^{* *}$ & $0.339^{* *}$ & $0.160^{* *}$ & $0.116^{*}$ & 0.881 \\
Iinnovative ability & $0.288^{* *}$ & $0.159^{* *}$ & 0.10 & \\
\hline
\end{tabular}

Note:**. significant correlation at. 01 level (bilateral) was observed. *. Significant correlation at 0.05 (bilateral) level. N=328.

\subsubsection{Research Hypothesis Verification}

This paper uses correlation analysis and regression analysis to verify the proposed research hypothesis. The correlation analysis of Table 3 shows that the correlation coefficients of flattening and decentralization on perceptive ability, integrative ability and innovative ability are 0.378 , $0.490,0.288 ; 0.156,0.399,0.159$, respectively, which are significantly correlated at the significant level of 0.01 . Then, linear regression analysis is used to confirm and judge whether there is causality between variables. The two dimensions of organizational structure are flattened and decentralized into independent variables of regression analysis, and the three dimensions of dynamic capabilities, perceptive ability, integrative ability and innovative ability are dependent variables. The results of regression analysis are shown in Table 4. As can be seen from the data in table 4, the correlation coefficients at $\mathrm{p}<0.05$ significant level are $0.378,0.490$ and 0.288 , respectively, indicating that flattening has a positive and significant effect on perceptive ability, integrative ability and innovative ability. The correlation coefficients of decentralization on perceptive ability, integrative ability and innovative ability are 0.156 , 0.339 and 0.159 , respectively, showing that decentralization has a positive effect on perceptive ability, integrative ability and innovative ability. The six hypotheses proposed in this paper are verified.

Table 4. Regression tests of study hypotheses.

\begin{tabular}{lllll}
\hline Modle & & Regression coefficient & t & Sig. \\
\hline \multirow{2}{*}{ Perceptive ability } & Flattening & .378 & 7.378 & .000 \\
& Decentralizatio & .156 & 2.853 & .005 \\
Integrative ability & Flattening & .490 & 10.151 & .000 \\
& Decentralizatio & .339 & 6.514 & .000 \\
Iinnovative ability & Flattening & .288 & 5.424 & .000 \\
\hline
\end{tabular}




\section{Conclusions and Management Implications}

\subsection{Conclusions}

The rapid development of the Internet era brings enterprises into a super competitive environment. Under this situation, the emergence and disappearance of competitive advantage of enterprises has gradually become a short concept of time. The concept of dynamic ability reveals the source of sustainable competitive advantage in dynamic environment, which is of great significance for enterprises to perceive environmental changes, integrate internal and external resources and innovate in time to establish sustainable competitive advantage. At the same time, as the carrier of enterprise dynamic capabilities, a series of new phenomena presented by organizational structure in the Internet era deserve attention. According to the existing theoretical basis, this paper deeply explores the influence of organizational structure on the dynamic capabilities of enterprises in the Internet era through the combination of literature research and empirical test, and obtains the following conclusions:

Firstly, the Internet era has subverted the traditional organizational management forms of enterprises, and the organizational structure has developed in the direction of flattening and decentralization. The three laws of the Internet reveal the irresistible and irreversibility of the development of the Internet. Its "bottom-up" and "decentralization" characteristics redefine the relationship between enterprises and consumers. Customer demand drives enterprises to provide corresponding products and services. Under this premise, the information of market demand must be transmitted in the organization briefly and quickly to realize the rapid cooperation of various departments. Therefore, while the scale of the organization is expanding, it is the inevitable result of the Internet era to expand the management range, reduce the organizational level and empower the grass-roots employees.

Secondly, the organizational structure of the Internet era has a significant impact on the dynamic capabilities of enterprises. The regression analysis shows that the flattening of organizational structure will positively affect the ability of perception, integration and innovation, and the decentralization of organizational structure will positively affect the ability of perception, integration and innovation. That is, the flat organizational structure in the Internet era, the higher the degree of decentralization, the more conducive to the construction of enterprise perceptive ability, integrative ability and innovative ability.

\subsection{Management Implications}

In the Internet age, enterprises need to pay attention to the adaptive change of organizational structure. In the Internet era, enterprises must use the fastest response speed to capture the changes of consumer demand, and the traditional "pyramid" organizational structure greatly inhibits the enthusiasm of employees. The flat and decentralized organizational structure aims to break through the traditional organizational rigid boundaries, make the organizational boundaries blurred, cross-departmental cooperation regular, decentralization. Accelerating the efficiency of diffusion and penetration of various knowledge information in the organization, helps enterprises overcome "big enterprise disease ", and form the ability to obtain sustainable competitive advantage in dynamic environment.

Enterprises must attach importance to the construction of dynamic capabilities and actively expand the depth of dynamic capabilities. In terms of perceptive ability, strengthen the ability to predict the direction of market demand, scan new market opportunities and threats, and respond quickly. In terms of integrative ability, we should strengthen inter-industry cooperation with other enterprises to set up strategic alliances to open up markets, adopt project team organization model to improve team's rapid coordination ability, and systematically formulate talent training programs. Ensure that the company can focus on current resources to key projects. In the aspect of innovative ability, we should formulate effective assessment methods for employees' innovation, encourage employees to carry out innovation and change activities, affirm employees with strong innovation ability and formulate corporate culture that helps employees put forward creative ideas.

The contribution of this paper is to sort out the two dimensions of flattening and decentralization through the evolution of organizational structure, and try to establish a relationship between organizational structure and dynamic ability. From the perspective of dynamic capabilities analysis, this paper holds that flat and decentralized organizational structure is an effective choice of enterprise organizational structure. The flat and decentralized organizational structure is more beneficial to the formation of enterprise dynamic cpaabilities. It can perceive the rapid changes of the market, integrate the internal and external resources efficiently, and obtain the competitive advantage of iterative rolling through the innovation of technology and management.

\subsection{Research Limitations and Prospects}

This paper studies the relationship between organizational structure and dynamic ability of enterprises in the Internet era. In view of the limitations of the author's research related resources, as an exploratory study, this paper has some limitations.

First of all, there are limitations in the sample data collected in the empirical analysis. The sample of the study is mainly collected through the form of network questionnaire. The object of investigation is based on the subjective understanding of the questionnaire, and some of the questionnaires may be objective. In the follow-up study, we can increase the reliability and validity of the verification data by expanding the sample size, so as to expand the difference of the sample statistics such as the nature of the enterprise and the scale of the enterprise, and enhance the width and breadth 
of the empirical research.

Secondly, the research on the external environmental factors, that is, the Internet era, needs to be improved. When considering the external environment and other factors that affect the organizational structure, this paper lists the development law of the Internet era and its influence on the organizational structure in the theoretical part, but limited to the lack of research in the relevant literature at present. In the process of follow-up research, we can consider qualitative research on environmental factors, divide them into dimensions, and test and perfect the influence of Internet era on organizational structure and dynamic capabilities of enterprises more accurately.

Finally, in the process of this study, the influence of variables such as regulation and mediation is ignored. This paper only studies the relationship between organizational structure and dynamic capabilities as independent variables, and does not discuss the deeper influence mechanism. The follow-up study can consider adding adjustment or intermediary variables, such as organizational learning, to explore the influence of organizational structure on dynamic capabilities in different situations by adding adjustment variables and intermediary variables. At the same time, in the Internet era, there are new enterprise organization management models such as internal entrepreneurship and shared organization. Enterprises should pay attention to cultivating competitiveness through dynamic capabilities, which is of great significance to guide enterprises to adapt to environmental changes quickly.

\section{Acknowledgements}

Thanks to the National Natural Science Foundation of China for the project "Micro Mechanism of Enterprise dynamic capabilities formation: Based on the Perspective of flexible Human Resource Management Innovation "(71662018). This paper is one of the research results of this project. At the same time, We would like to thank the all scholars in the references for their foundation, inspiration and promotion to this paper.

\section{References}

[1] Vergne, J. P., Durand, R. (2011). The Path of Most Persistence: An Evolutionary Perspective on Path Dependence and Dynamic Capabilities. Organization Studies, 32.

[2] Teece, D. J., Pisano, G., \& Shuen, A. (1997). Dynamic capabilities and strategic management. Strategic Management Journal, 18: 509-533.

[3] Barreto, I. (2010). Dynamic capabilities: A review of past research and an agenda for the futur. Journal of Management, 36: $256-280$.

[4] Dai Tianjing, Tang Guliang, Peng Jiajun. (2012). The case study of enterprise dynamic capabilities enhancement, organization structure inversion and new management control system embedded — based on Haier group self-management exploration. China Industrial Economics. 2: 128-138.
[5] Li Pengbo, Liang Han. (2017). Research on Evolution Mechanism of Enterprise Organization Structure Based on Value Creation Perspective — Taking Alibaba Group as an Example. Hubei Social Sciences, 2: 104-111.

[6] Feng Junzheng, Wei Jiang. (2011). A Review and Prospect of Dimensional Division and Measurement of Foreign dynamic capabilities. Foreign Economics \& Management, 7: 26-33.

[7] Drucker., P. F (1988). The coming of new organizations. Harvard Business Review.

[8] Peters, T. J. (1992). Liberation of management; necessary disorganization for the nanosecond nineties. New York: Alfred P. Knopf.

[9] Zhao Wen. (2001). Causes and Countermeasures of Enterprise Organization Pattern Innovation in Network Age. XueHai, 4: 71-75.

[10] Hu Guodong, Wang Xiaojie (2019). Evolutionary Logic and Self-organization Mechanism of Platform Enterprises. China Soft Science Magazine, 3: 143-152.

[11] Mintzberg H, Hall P (1979). Structuring of Organizations. Chemische Berichte, 130 (5): 621-631.

[12] Daft, R. L. Organization Theory and Design. South Western Educational Publishing: Cincinnati, OH. 2009.

[13] Lawrence, P. R, \& Lorsch, J. W (1967). Differentiation and Integration in complex organizations. Administrative Science, 12: $1-47$.

[14] Luo Min, Zhou Siwei. Complexity of Organizations (2011). Foreign economy and management, 33 (1): 26-33-42.

[15] Ramezan, M (2011). Intellectual Capital and Organizational Organic Structure in Knowledge Society: How Are These Concepts Related? International Journal of Information Management, 31 (1): 88-95.

[16] Chen Guoquan, Liu Wei (2017). An empirical study on the impact of enterprise environment on exploratory learning and applied Learning and Its Balance, China Soft Science Magazine, 3: 99-109.

[17] Wang Tao, Lu Yuxin, Jin Luoxin (2018). Research on the Influence of Organic Structure on the Performance of Reverse Internationalization from based on the dynamic capabilities. Chinese Journal of Management Journal, 5 (2): 174-182.

[18] Cardinal, L. B (2001). Technological innovation in the pharmaceutical industry: The use of organizational control in managing research and development. Organization Science, 12 (1): 19-36.

[19] Jansen,. J. P, Van Den Bosch, F. A. J, \& Volberda, H. W (2006). Exploratory innovation, exploitative innovation, and performance: Effects of organizational antecedents and environmental moderators. Management Science, 52 (11): 1661-1674.

[20] Eisenhardt K. M, Martin J. A (2000). Dynamic Capabilities: What are They? Strategic Management Journal, 21 (10): 1105-1121.

[21] Zollo M, Winter S G (2002). Deliberate Learning and the Evolution of Dynamic Capabilities. Organization Science, 13 (3): 339-351. 
[22] Helfat, C. E. \& Winter, S. G (2011). Untangling Dynamic and Operational Capabilities: Strategy for the Ever-Changing World. Strategic Management Journal, 32 (11): 1243-1250.

[23] Luo Min (2010). Analysis on evolution and development track of organizational design thought. Foreign Economics \& Management, (4): 128- 132.

[24] Wang C. L., \& Ahmed P. K (2007). Dynamic Capabilities: A Review and Research Agenda. International Journal of Management Reviews, 9 (1): 31-51.

[25] Huang Jiatang (2017). The Influence of Enterprise Dynamic Capabilities on Value Creation: A Perspective of Creative Experience. Enterprise Economy, 8: 30-37.

[26] Hu Chunhui, Xu Guojun, An Yi (2016). Research on organizational structure reengineering and accounting method based on dynamic capabilities enhancement. Contemporary Finance, 1: 108-120.

[27] Xiao Hongjun, Li Miaomiao (2012). Research on Dimensional Division of Dynamic Capabilities — Based on Haier's Case Study. Journal of Management Case Studies, 5 (2): 77-85.

[28] Tsoukas, H., \& Mylonopoulos, N. (2004) Introduction: What does it Mean to View Organizations as Knowledge Systems?. Organizations as Knowledge Systems. Palgrave Macmillan UK.

[29] Martínez - León, I. M, \& Martínez - García, J. A (2011). The influence of organizational structure on organizational learning. International Journal of Manpowe, 32 (5/6): 537-566.

[30] Bapuji, H., \& Crossan, M. (2013) From Questions to Answers: Reviewing Organizational Learning Research. Management Learning, 35 (4): 397-417.

[31] Zahar, S. A., George, G (2002). Absorptive capacity: A review, reconceptualization, and extension. Academy of Management Review, 27 (2): 185-203.

[32] Huang X, Kristal, M. M, Schroeder, R. G (2010). The Impact of
Organizational Structure on Mass Customization Capability: A Contingency View. Production \& Operations Management, 19 (5): 515-530.

[33] Salunke, S, Weerawardena, J, Mccoll-kennedy J R (2011). Towards a model of dynamic capabilities in innovation-based competitive strategy: Insights from project-oriented service firms. Industrial Marketing Management, 40 (8): 1251-1263.

[34] He Xiaogang, LiXinchun (2006). Measurement and Effectiveness of Dynamic Capabilities: An Empirical Study Based on Chinese Experience. Management World, 3: 94-103.

[35] Luo Min, Li Liangyu (2015). Innovation of Business Model in Internet Age: Value Creation Perspective. China Industrial Economics, 1: 95-107.

[36] Rindova, V. P., Kotha, S (2001). Continuous "morphing ": Competing through dynamic capabilities form and function. Academy of Management Journal, 44: 1263-1280.

[37] Linderman, K., Schroeder, R. G,. \& Zaheer, S (2004). Integrating Quality Management Practices with Knowledge Creation Processes. Journal of Operations Management, 22 (6): 589-607.

[38] Jensen, M. C (1992) Specific and General Knowledge and Organizational Structure. Journal of Applied Corporate Finance.

[39] Chen Jianjun, Wang Zhengpei, Li Guoxin (2018). Organizational Structure and Innovation Performance of Chinese Aerospace Enterprises: The Intermediary Effect of Dynamic Capabilities and Innovation Atmosphere. China Soft Science Magazine, 11: 122-130.

[40] Aiken, M., \& Hage, J (1971). The Organic Organization And Innovation. Sociology, 5 (1): 63-82.

[41] Debra. Emilton (1998). Innovation Strategy of Knowledge Economy. Xinhua Press. 